\title{
Internal Evaluation: A Synthesis of Traditional Methods and Industrial Engineering
}

\author{
JONATHAN A. MORELL
}

\begin{abstract}
In evaluation as it has been practiced, requirements for specialized training have caused a trade-off between rigor of method and the extent of program staff's involvement in the evaluation process. There is a way to remove the trade-off between "rigor" and "use," by applying industrial engineering (IE) tools that, though sophisticated and powerful, are packaged to facilitate use by people with relatively little specialized training. One level of IE use in evaluation simply adds tools to the evaluators' toolbox. The second level employs the methodological abilities of evaluators to adapt and improve IE tools. Several problems must be solved in order to achieve the necessary integration. These include inserting the new evaluation technology into program settings, training and education, and developing a different kind of relationship between professional evaluators and those who work in settings where evaluation takes place.
\end{abstract}

\section{INTRODUCTION}

In this paper I offer a strategy for simultaneously improving the methodology and utilization of internal evaluation. The key notion in the proposed strategy is that program improvement is best served by an integration of two traditions: traditional program evaluation, with its roots in economics, political science, sociology, psychology, and anthropology; and Industrial Engineering (IE), with a particular emphasis on its "quality improvement" methods. Together, these traditions can compensate for each other's weaknesses and augment each other's strengths, thereby generating internal evaluation systems that are for more useful than either could be alone. First, I will present a case for simply adding some IE tools to the evaluator's toolkit. More tools, more choices, a better evaluation. Then, I argue in favor of an actual integration of the evaluation and IE perspectives. With such an integration,

Jonathan A. Morell, • ERIM—Center for Electronic Commerce, PO Box 134001, Ann Arbor, MI 48113-4001; Tel.: (734) 623-2520; Fax: (734) 623-2501; E-mail: jmorell@erim.org.

American Journal of Evaluation, Vol. 21, No. 1, 2000, pp. 41-52. All rights of reproduction in any form reserved. ISSN: 1098-2140

Copyright (C) 2000 by American Evaluation Association. 
evaluation could be used to increase the quality of IE tools, which could then be used to further improve the way evaluation is done. I conclude with a discussion of how the recommended integration might be achieved.

My proposals lie generally within what is known as "formative evaluation." In making this argument, I do not mean to imply that summative evaluation does not matter. I only claim that formative evaluation does matter, that it consumes a good deal of our efforts, and that it is likely to continue to do so for the foreseeable future. As long as that is the case, we have an obligation to seek ways to improve our ability to assist with program improvement. My proposed strategy for meeting this obligation advocates a decentralized approach to internal evaluation, that is, a method that locates evaluation as closely as possible to the object of the evaluation. Following Sonnichsen's (1999) analysis of the relative merits of centralized and decentralized evaluation, I believe that when program improvement is the evaluation goal, intimate knowledge of a setting is more important than the increased objectivity that flows from a more distant, centralized evaluation group.

\section{THE PRESENT STATUS OF TRADITIONAL EVALUATION}

The power of evaluation lies in the number, variety, and capabilities of the tools it can bring to bear on the problem of finding out what a program is doing, and why. Its armamentarium is enormous. Sampling methods are finely tuned so that evaluation can structure samples that represent complex populations, make informed trade-offs of sample size and accuracy, and correct (partially) for bias. Research designs inform about causality. Data reduction and structure discovery techniques help us avoid being overwhelmed with data, and inform us as to which numbers are truly relevant. Measurement and instrument development procedures help us understand what is being measured, and how well. Qualitative methods such as interviewing, focus groups, observation, and methods for structure discovery yield a very great deal of useful information.

While powerful and useful, these techniques are inaccessible to most program staff. Even for minimal use, most of these methods require special knowledge and a level of skill that is unreasonable to expect from those involved in planning, management, or service delivery. Even qualitative methods, which at some level are accessible to people without special training, soon run into limitations due to lack of expert knowledge.

As an example of how qualitative methods are limited when used by laypersons, consider observational methods. Anyone can observe events and do a good job of extracting meaning from the observations. But it takes considerable expertise to look at events and interpret them in terms of an economy, power, or information transmission. To get that meaning, it takes a trained ethnographer who can employ theory-based insight to extract latent meaning.

Because evaluation methods require expert knowledge, the success of evaluation often depends on how well knowledge transfer can be effected between two distinct communities, that is, knowledge transfer must occur from evaluators to the service providers, managers, and leaders who keep programs working. The field of evaluation has developed an enormous literature and much craft aimed at dealing with this problem of knowledge transfer. Many of these techniques work, but they require a concerted and specially designed effort to assure that the information generated by evaluators is both usable and used by decision makers.

Knowledge utilization tactics can be seen as a way to increase interaction between two 
communities-evaluators and program staff. The tactics are needed because of an organizational/professional/epistemological separation between those charged with doing evaluation, on the one hand, and those charged with providing service or management, on the other. I categorize evaluation of this type as the low staff involvement approach. It is this form of evaluation that relies so heavily on "bridging tactics" to establish a relationship between the community of evaluators and the community of service and management.

Another approach to evaluation requires high staff involvement as an integral part of the evaluation enterprise. With this type of evaluation, the distinction between the evaluators and program staff disappears, or at least is greatly blurred. As an example, in "empowerment evaluation" program personnel actively design and execute evaluations (Fetterman, Kaftarian, \& Wandersman, 1996). High staff involvement is important because it promotes utilization. For example, as part of his effort to develop a meta-model of utilization, Johnson (1998) cites several empirical studies that support the importance of staff involvement in the utilization of evaluation results.

\section{The Low Staff Involvement Approach}

There are two fundamental problems with the "low staff involvement" method. The first is that, left to their own devices, evaluators tend to employ the best and most powerful methods they have, regardless of the accessibility or face value of those techniques to people not schooled in the ways of social research. (In fact, some of the most powerful techniques often make the least sense to those without technical training.) As a result, evaluators shoulder a heavy burden late in the evaluation process when they must explain to a non-technical and possibly skeptical audience the practical value of their esoteric methods.

The second problem relates to the length of evaluation feedback loops relative to the pace of program change. Programs exist in uncertain environments, with factors such as service delivery requirements, funding, programming options, and the availability of replacement personnel in a constant state of flux. As a program's objectives and windows of opportunity change, so too will its needs for evaluation. Many of social science's best methods, however, demand a certain degree of stability. It is hard to plan data collection methods, maintain instrument validity, and follow data collection schedules when a program is undergoing too much change.

\section{The High Staff Involvement Approach}

The basic problem with maximum staff involvement is the lack of methodological expertise by people who are experts in their fields but not trained to do rigorous evaluation. Some thoughtful work has been developed to derive as much value as possible from methods that can be applied by people without deep methodological expertise (e.g., Fowler, 1998; Mangione, 1998; Morgan \& Krueger, 1998). While these techniques are useful and accessible, there is no denying their weaknesses relative to sophisticated stratified sampling, powerful research designs, deep exploration of data structure, and carefully validated instruments.

In short, when ongoing program improvement is the objective, the high and low staff involvement approaches offer a trade-off between the ability to generate information and the likelihood that evaluation results will be used by program staff to guide their decisions. To 
illustrate this trade-off, consider an example based on a public mental health system in a large urban area. ${ }^{1}$

\section{Example: Comparison of High and Low Staff Involvement Approaches}

Organizational setting of the case: Mental health service system in a large urban area. A multi-site system with five sites around the city. Each site caters to a mix of clients from different racial and ethnic backgrounds, with the mix differing by clinic.

Presenting problems: The proportion of presenting problems at the clinics differs. For example, some have a large number of substance abuse cases, while others have many fewer. Some get a great many school referrals. One area has a population which is older than average, and thus sees a lot of geriatric cases.

Staff: While staffing differs a bit for each center, a typical workforce for each consists of one psychiatrist, one psychologist, one social worker per case management team, and various paraprofessional staff members who work directly with the clients as case managers. With greater variation across centers, it is possible to find physical therapists, art therapists, recreational therapists, and vocational counselors. Each clinic has some discretionary funds that it uses to bring in clinical help when there are surges in the caseload. Case management teams are headed by social workers. Each clinic has a part-time evaluator who does double duty at other tasks. In most cases, the double duty involves some form of clinical work, but in one center the part-time evaluator also runs the information system. The evaluators' training and expertise are in their primary fields-clinical social work or information systems.

Environmental pressures on the clinics: Demographics in the city are changing. In particular, the African-American population is stable, but the number of Asians and Hispanics is increasing. Also, budget pressures and managed care are resulting in an ever-greater emphasis on treatment efficiency and analysis of client outcome.

Clinics' response to environmental pressures: Because of the emphasis on efficiency, the role of case manager is becoming more important. The case manager is coming to be seen as the key person to keep costs down by making sure that client care is coordinated, and that clients do what is necessary to avoid more expensive treatment (e.g., taking medication or getting into skills training workshops). Also, it is expected that the case manager will keep in touch with clients, with an eye toward detecting signs of relapse.

Current evaluation activities: In the main, evaluation has involved "eyeball" tracking of patient and treatment patterns. For example, for therapeutic impact, the length of stay in treatment, and the level of functioning at entry and exit have been tracked. For needs analysis, changes have been measured in patient demographics, and in presenting problems of new patients. For clinic efficiency, the clinics measure patient load for each case manager, expenditures per client, number of different services per client, and correspondence of treatment plans among therapists.

Limitations on current evaluation activities: The critical limitation in the present evaluation approach is the inability to understand changing patterns. The problem is twosided. First is the well-known human proclivity to find patterns where none exist. It is quite possible that what looks like a trend or a difference among groups may not be real. For instance, is an increase in referrals from schools a real change in the needs of the community, or is it just normally occurring fluctuation? Is the difference in level of functioning of patients from intake to release really narrowing, or is the change illusory? The answers make a difference because they will drive practical decisions. 
It is equally possible that without statistical analysis techniques, important trends and group differences would not be detected. Are case managers becoming more effective? The answer to this question may require a carefully developed and validated composite scale consisting of cost, length of stay in treatment, and treatment mix. Are seeming increases in costs actually desirable because the severity of patient needs is increasing and, relative to past costs for these types of patients, the clinic is really doing quite well? None of these questions can be answered without esoteric techniques for instrument development and data analysis, and a great deal of specialized expertise in data collection, management, and interpretation.

Limitations on utilization: Evaluators may be able to address some of these questions, but to do so they will need to employ esoteric methods whose logic and justification are obscure, and whose results may contradict cherished beliefs. Essentially, this is a situation in which evaluation can produce a great deal of information but because of the tools needed to get that information, the level of staff involvement and, hence the likelihood of use, are low.

Evaluators are well aware of how some of their best methods seem the least sensible to people not schooled in the use of those methods. I believe there is an opportunity to alter this situation so that methodologically sophisticated evaluation can take place under conditions of "high involvement".

\section{INCORPORATING INDUSTRIAL ENGINEERING INTO EVALUATION}

Consider the tools of IE. Many of them are based on the principle that those involved in a process are the best ones to evaluate it. Thus, IE tools are designed and packaged to be used with minimal assistance from specially trained experts. Examples of these tools include total quality management, Pareto analysis, Deming cycles, root cause analysis, and business process reengineering. While these tools may need expert assistance, and while many rely on complex mathematics, they are all devised with the intention that their primary users be as close as possible to practitioners in the process under investigation. (For overviews of these tools see Akiba, Schvaneveldt, \& Enkawa [1992]; Melnyk \& Denzler [1996]. For examples of how these tools could be applied in evaluation settings, see the Green [1999] series in Evaluation and Program Planning, devoted to the application of Total Quality Management in health care evaluation.)

These tools have a rigor, and often a quantitative foundation, not found in the other tools that evaluators have given to program staff. By applying IE tools, program staff can have more information-generating capacity than ever before. Two examples of how these tools can be applied are Quality Function Deployment (QFD) and control charting (CC).

Quality Function Deployment (QFD) is an example of a technique that helps people articulate the relationship between customer needs and the detailed specifications required to actually design a product. (I will leave aside the question of when and whether a "need" is really a "want," as the answer does not affect this discussion. Our discipline is generally comfortable with the term "need," so I use that term here.) The strength of QFD lies in its ability to assure that original intent is the guiding force behind detailed decisions that are made as the product evolves. As an example, in designing the power train of an automobile, decisions need to be made about engine displacement, power, and gearing. Each of these, in turn, requires numerous other design decisions. Taken together, the process involves numerous trade-offs that have consequences for how the car behaves in ways that customers care 
about, such as acceleration, towing power, fuel economy, purchase cost, reliability, and repair cost. The QFD process begins with an assessment of which of these characteristics are most important, and then provides a mechanism for tracing the logic of decisions back to the original set of consumer needs. For example, a decision about using a particular alloy in the engine could be traced back to priorities that ranked reliability as far more important than fuel economy, acceleration, or purchase cost. Had the original priorities been different, the specific decision to use that particular material may have been different. In essence, QFD helps assure that what is built is what was intended to be built, and that what was intended to be built meets the needs of its users.

QFD was originally intended for design engineering in product development. It can, however, be useful for designing services as well, and therein lies its value for the kind of work that most evaluators do. To illustrate, let us build on the mental health example presented earlier. In that example, demographics are changing. Let us assume that a needs assessment has established that a particular area has a growing number of families who are raising children and that, as a consequence, service priorities must focus more on youth services, marriage counseling, and parenting skills. Once needs are established, the next QFD step is to identify a general set of characteristics ("features" in QFD-speak) of a mental health services program that would meet the identified needs. The principle at this stage is not to delve into great detail, but to produce an understanding of what the program would "look like" if it were to meet identified needs. For instance, the statement "acquire more expertise in youth and family counseling" would be appropriate, although it would not be appropriate to make a pronouncement such as "hire two more youth and family counselors." Why is the first level appropriate at this stage and the second not? Because "hiring more counselors" is but one of many ways for the clinic to acquire the necessary skills. Alternatively, the clinic could decide to retrain existing staff or to contract for the services with independent practitioners. It is too early to decide whether more hires are needed, but it is the right time to be clear that more youth and family expertise is required.

To continue the example, the QFD exercise may reveal three important features for the redesigned program: (1) effective coordination with those groups in the community that deal with youth (schools, police, churches, welfare), (2) fast response to crisis situations, and (3) more expertise in youth and family counseling. Once the important features have been identified, experts and a consensus-building process are used to determine two sets of parameters: (1) the relative importance of each customer need, and (2) the relationship between each need and each program feature. As an example, consensus may reveal that "youth services" are the single most important need. There may also be consensus that, to meet this need, it is highly important to have a clinic with "youth and family" expertise and to have good "coordination mechanisms," but that "fast crisis response" is of minimal importance in assuring that the "youth services" requirement is met. (The traditional scaling method for assessing relationships is: $9=$ strong, $3=$ medium, $1=$ weak, and $0=$ none.) All of this information is concisely summarized as shown in Table 1 . The result of this exercise is a clear statement about what features the clinic must have if it is to meet its most important customer needs.

It now becomes possible to move to the next level of detail, which is an assessment of what specific operations are needed to achieve a program with the already determined characteristics. This is done by arranging program characteristics, which appeared as columns in Table 1, as rows in a second matrix, and then listing all the specifics which may be needed to achieve those characteristics. An example is provided in Table 2. 
TABLE 1.

Relationships Among Needs and Program Characteristics

\begin{tabular}{|c|c|c|c|c|}
\hline \multirow[b]{2}{*}{$\begin{array}{l}\text { Customer } \\
\text { need }\end{array}$} & \multirow[b]{2}{*}{$\begin{array}{l}\text { Need } \\
\text { priority }\end{array}$} & \multicolumn{3}{|c|}{ Features } \\
\hline & & Coordination & $\begin{array}{l}\text { Fast crisis } \\
\text { response }\end{array}$ & $\begin{array}{c}\text { Youth and } \\
\text { family expertise }\end{array}$ \\
\hline $\begin{array}{l}\text { Youth services } \\
\text { Family counselin } \\
\text { Parenting skills } \\
\text { Col. Sum. }\end{array}$ & & & & \\
\hline
\end{tabular}

Once this matrix is constructed, another group exercise is conducted to build priorities among the row x column combinations. What emerges is an understanding of what specific actions are needed if the clinic is to have the desired characteristics. To carry through the example from Table 1, we may have established that "fast crisis response" is a high priority. It may emerge from Table 2 that, in order to achieve such response, critical specifications are "school site programs" and all the "regular meetings" specifications. The process of setting priorities for ever more specific actions can be repeated for as long as it takes to get to a list of actionable tactics for program building. Because each matrix is linked to those adjacent to it in the hierarchy, it will always be possible to link the objectives that drove program change, in the first place, to specific, detailed actions. (This is a simplified presentation of QFD. Two of many noteworthy aspects of the process include looking for features that are synergistic or in conflict, and comparing different proposed designs.)

In essence, QFD is a method of developing a powerful theory of program action, a theory that can guide both program development and program evaluation. Would a QFD process be useful in a real case of the redesign of a mental health system? Not if priorities were well known, consensus on action was readily achievable, required actions were few in number and independent of each other, the shape of the new program was simple, and pressures to veer from design intent were slight. On the other hand, the greater the ambiguity, complexity, and pressure for pushing program design in multiple directions, the more appealing this kind of a structured process becomes.

TABLE 2.

Relationships Among Program Characteristics and Specifications

\begin{tabular}{|c|c|c|c|c|c|c|c|}
\hline \multirow[b]{2}{*}{$\begin{array}{c}\text { Program } \\
\text { Characteristics }\end{array}$} & \multirow[b]{2}{*}{ Priority } & \multicolumn{6}{|c|}{ Specifications } \\
\hline & & $\begin{array}{c}\text { School } \\
\text { site } \\
\text { programs }\end{array}$ & $\begin{array}{l}\text { Regular } \\
\text { meetings } \\
\text { with } \\
\text { police }\end{array}$ & $\begin{array}{l}\text { Regular } \\
\text { meetings } \\
\text { with } \\
\text { church } \\
\text { leaders }\end{array}$ & $\begin{array}{c}\text { Hire a } \\
\text { family } \\
\text { counseling } \\
\text { expert }\end{array}$ & $\begin{array}{c}\text { Staff } \\
\text { training } \\
\text { in family } \\
\text { counseling }\end{array}$ & $\begin{array}{l}\text { Data base } \\
\text { to track } \\
\text { clients' } \\
\text { school } \\
\text { behavior Etc. }\end{array}$ \\
\hline $\begin{array}{l}\text { Coordination } \\
\text { Fast crisis response } \\
\text { Youth and family } \\
\text { expertise } \\
\quad \text { Col. sum. }\end{array}$ & & & & & & & \\
\hline
\end{tabular}


Control Charting is a means by which participants in a process assess the functioning of their system based on (1) historical knowledge of how an indicator has changed, and (2) the statistics of variation. Using this knowledge, "limits" are set at a chosen confidence interval (as defined statistically) and data are tracked over time. Variation within the limits is regarded as random, while variation outside the limits, or trends moving toward a limit, are cause for concern. Control charting is usually used in manufacturing settings to look for variances in product specifications (e.g., dimensions of a ball bearing, shear strength of a rod), or in production processes (e.g., heat in a drying oven, speed of an assembly line). There is no reason, however, why control charting could not be applied to the activities that go on in the mental health system we have been using as an example. For instance, it could be used to track dropout rates, client functioning measures, speed of response to crises, cost per patient, or demographic descriptions of clients.

Control charting is, in essence, a highly developed form of what evaluators call "performance monitoring." One difference between the two is that control charting comes with a highly developed craft to assure that a variety of processes within an organization are assessed with appropriate metrics by those who are best able to act on the information. A second important difference is the rigor and quantitative treatment of trends, variance, and confidence limits that are embedded in the method's well-developed procedures and algorithms. Certainly, those who do process charting need special skills to sample data correctly and do the calculations needed to determine appropriate confidence intervals. Those skills, however, can be cast as routine operations, and do not require the deep expertise of the statisticians who worked out the system in the first place. (A good overview of how the calculations are actually done can be found in Melnyk \& Danzler [1996].)

Figure 1 presents hypothetical data to show how control charting might be used in the mental health example. Four system indicators are tracked over time: clinical change in patients, waiting time from referral to first session with a therapist, number of active clients, and monthly expenditures for part-time, surge capacity clinical help. In each case, 95\% confidence intervals are set around each indicator. Figure 1 contains three possible patterns of data. The top set of data indicates an impending budget crisis. Service quality (as measured by outcome and wait time) is being maintained even though the client census is increasing. This state of affairs is being sustained, however, by increasing use of the limited funds available for part-time assistance. The second set of data bodes ill. Caseload is increasing, wait time is tending upward, outcome is dropping, and expenditures for part-time help are decreasing (perhaps because the kitty is running dry). The third data set is more sanguine than the second. The same resource constraints are present, but the clinic seems to be dealing with the problem reasonably well by allowing wait time to increase in order to maintain client outcome.

\section{BEYOND THE SIMPLE COMBINATION OF METHODS}

While combining traditional evaluation and IE is worthwhile, something more is needed. The evaluation and IE approaches must be integrated to achieve a state in which informationgenerating capacity rises to previously unobtainable levels, and because of that increase, utility will also go up.

To achieve this new order, we need a vision of how evaluation tools can increase the potency of IE tools. Support from evaluation is needed because many of the assumptions 

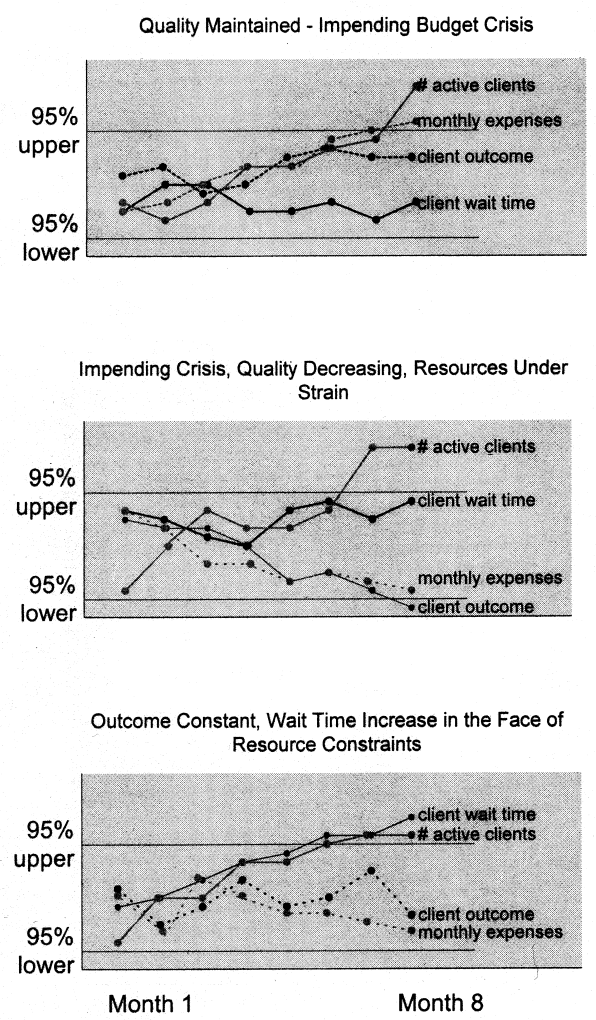

Figure 1. Charting the System's Performance

underlying IE tools are tenuous, even when those tools are applied for their original intended purpose, that is, to improve the quality of manufactured goods. These assumptions seem even less certain when applied to service programs that are characterized by multiple paths to a variety of outcomes, by many different bundles of services, by intermediate progress that is hard to measure, and by client populations that are in flux. When these types of uncertainties exist, those applying IE tools would do well to collaborate with experts in evaluation methodology. The evaluation perspective would provide improvements that span the gamut of the concerns about methodology, including issues such as the reliability and validity of measurement, representative sampling, the contextual meaning of data, attribution of causality, instrument construction, and data collection. How this collaboration might work is illustrated in Table 3, which draws from the examples used in this paper. Running throughout the illustrations in Table 3 is the theme that methodologies used in evaluation can be applied to validate and strengthen the power of IE tools.

\section{Achieving the Integration}

The challenge is to establish an organizational system that meets three requirements. It must keep evaluation in the hands of program staff. It must employ the tools of IE. It must augment those tools with the power of traditional evaluation. There is no immediate 
TABLE 3.

Assumptions and Role of Evaluation

Assumption in QFD and CC Examples

1. We can accurately and consistently observe process variation. (CC)

2. Program staff know the best indicators of program action. (CC)

3. Program staff can determine appropriate upper and lower limits for important program indicators. (CC)

4. Intuitive analysis of trend lines can discriminate between true and random variation. (CC)

5. Program planners can accurately determine needs in a population. (QFD)

6. Program planners can make correct estimates of what program characteristics will yield particular outcomes. (QFD)

7. The "9-3-1" (strong, medium, weak) scaling method is a good way to relate needs to program features, or program features to detailed specifications. (QFD)

\section{Possible Evaluation Contributions}

Test which elements of program activity can be accurately judged, develop reliable observation schemes, assess metrics for reliability and validity.

Build and test models and theories of program action.

Testing of ranges of activities that result in outcomes within desirable limits.

Time series analysis.

Use experience and need assessment methodologies to determine the settings in which program planners can accurately do these assessments.

Systematic application of research literature to group decision making. Research on correctness of consensus decisions. Group process methodology.

Use psychometric approaches to assess the validity of the QFD rating method.

short-term solution to this challenge because at present the structure for success is lacking. To see why, view the evaluation/IE integration proposed here as a new technology. (In this discussion I am following the socio-technical change management tradition, which focuses on the importance of coordinated change in organizational and technological systems. See, for example, Pava [1986].) Is there any reason to think that any technology will be used successfully if it were dropped into a setting and its use mandated? Would a database be deployed successfully if it were dropped into an organization without user training, without a technical support system, and without organizational changes to assure that people receiving the data had the authority to act on it? Just as the database would fail to achieve its potential without attention to socio-technical considerations, so too would a new evaluation technology fail.

One requirement for success is a program setting in which most of the evaluation is in fact done by program staff. This is a non-trivial change, as anyone who has been involved in a total quality management or a business process reengineering exercise can attest. Success 
involves changes in an organization's culture, incentive systems, reporting relationships, and skill base. Those changes can happen only if program sponsors provide permission and freedom for change, along with incentives for success and penalties for failure.

Further, all involved have to accept the fact that if evaluation is the responsibility of program staff, relatively little of it will be done. It is all well and good to think of continuous improvement as part of everyone's job, but it is also important to remember that people need time to actually do their jobs. Staff need to use most of their time to perform core professional tasks, to engage in professional development, to fulfill reporting and accounting duties, and to provide assistance to colleagues. To make the proposed system work, all involvedservice providers, administrators, and sponsors - must learn to de-emphasize the quantity of evaluation and to reward effective evaluation instead. Because careful choices must be made about what evaluation is done, program staff will need powerful tools to help set evaluation priorities. For instance, it may be useful to develop simple ways to visualize needs, weigh priorities, or assess the risk of proposed program changes.

With respect to evaluation priorities, two important questions loom: Who should set the agenda, and what role should evaluators play in pursuing that agenda? I believe that the evaluation process should be driven by a program's management and service staff, with evaluators assisting and advising as needed. An ideal model for this arrangement is the industrial practice of concurrent engineering (CE), wherein cross-functional interdisciplinary teams bring collective wisdom to bear at all stages of a project's life cycle. One virtue of this model is that team's objectives are set by internal customers to whom the team is responsible. Because of this reward structure, special interests within a team cannot drive the group's agenda to meet parochial interests, including doing good evaluation just for its own sake.

A second advantage of the $\mathrm{CE}$ model is that by increasing the complexity and expense of coordination earlier in a project's life cycle, there is an overall decrease in expense and completion time. To illustrate the value of the $\mathrm{CE}$ approach in our context, consider three examples. First, it is better to detect potential bias in a sampling plan before data collection than to detect it as real bias in data that has already been collected. Second, it is easy to develop questionnaires and scales that have face validity, but in fact produce highly distorted data. It takes a considerable amount of social science expertise to get these instruments right. Third, in the messy world of comparing client groups, valid comparison can require a careful choice of information to be collected and sophisticated analysis to separate apparent from real differences. In each of these cases, evaluation expertise carries its greatest value if it comes prior to the time when particular decisions are made. To get that timely input, however, high levels of coordination are required at the early stages between evaluators and the other disciplines represented in the evaluation team.

Over and above manipulating incentive systems and changing organizational design, there is also need for long-term educational and research programs. One reason for this need is that we do not yet fully know the best ways to combine IE and evaluation methods. It is one thing to give reasonable advice; it is another to test what works and to push the frontiers of understanding. As an example, I have no idea to what degree instrument design and validation techniques can be packaged for ready use by people who are untrained in social science methods. What answer to this question would emerge from a collaboration between experts in instrument design and experts in rule-based systems?

A second issue is that the proposed integration of IE and evaluation is novel and will undoubtedly be uncomfortable for evaluators, program personnel, and perhaps even sponsors. No matter what the incentives, resistance by those involved can doom any efforts at 
change. Solutions include three types of training: short-term workshops, courses taken by evaluators during graduate training, and courses given to managers and policy makers during their graduate training. All are needed to build the common knowledge base and collective mind set that are needed to change the nature of intra-program evaluation activity.

\section{CONCLUSION}

Our field has a long history of incorporating methods from many disciplines into our particular view of what it means to value a program and how to go about the valuing. This paper is an effort to present yet another set of methods and to justify their inclusion in our toolbox. I hope that this paper sparks a dialog in the evaluation community, leading to the development and deployment of the proposed integration of IE and evaluation.

\section{ACKNOWLEDGMENTS}

Grateful thanks to the many people who provided comment and critique on this paper: Molly Engle, David Fetterman, Michael Fleischer, John Heilman, Rex Green, Mel Mark, Hans Torvatn, Carol Mowbray, Marge Pacer, Emil Posavac, and anonymous reviewers.

\section{NOTE}

1. This is a hypothetical example designed to reflect common realities in urban mental health systems. Special thanks to Rex Green for helping me work out the details.

\section{REFERENCES}

Akiba, M., Schvaneveldt, S. J., \& Enkawa, T. (1992). Service quality: Methodology and Japanese Perspectives. In G. Salvendy (Ed.), Handbook of industrial engineering, 2nd ed. (pp. 2349-2371). New York: Wiley.

Fetterman, D. M., Kaftarian, S. J., \& Wandersman, A. (1996). Empowerment evaluation: Knowledge and tools for self-assessment and accountability. Thousand Oaks, CA: Sage.

Fowler, F. J. (1998). Design and evaluation of survey questions. In L. Bickman \& D.J. Rog (Eds.), Handbook of applied social research methods (pp. 343-428). Thousand Oaks, CA: Sage.

Green, R. (1999). (Ed.). Special section: Total quality management in behavioral health care. Evaluation and Program Planning, 22, 179-243.

Johnson, R. B. (1998). Toward a theoretical model of evaluation utilization. Evaluation and Program Planning, 21, 91-110.

Mangione, T. W. (1998). Mail surveys. In L. Bickman \& D. J. Rog (Eds.), Handbook of applied social research methods (pp. 399-428). Thousand Oaks, CA: Sage.

Melnyk, S. A., \& Denzler, D. R. (1996). Operations management: A value driven approach. Chicago: Irwin.

Morgan, D. L., \& Krueger, R. A. (1998). The focus group guidebook, Vols. 1-6. Thousand Oaks, CA: Sage.

Pava, C. (1986). Redesigning sociotechnical systems design: Concepts and methods for the 1990s. The Journal of Applied Behavioral Science 22, 201-221.

Sonnichsen, R. C. (1999). Building evaluation capacity within organizations. In R. Boyle \& D. Lemaire (Eds.), Building effective evaluation capacity: Lessons from practice (pp. 53-74). New Brunswick, NJ: Transaction. 